\title{
Secreted aspartic proteases are not required for invasion of reconstituted human epithelia by Candida albicans
}

\author{
Ulrich Lermann and Joachim Morschhäuser
}

Correspondence

Joachim Morschhäuser

joachim.morschhaeuser@mail.uni-

wuerzburg.de

Received 22 July 2008

Revised 4 August 2008

Accepted 11 August 2008

\author{
Institut für Molekulare Infektionsbiologie, Universität Würzburg, Röntgenring 11, D-97070 \\ Würzburg, Germany
}

\begin{abstract}
A well-known virulence attribute of the human-pathogenic yeast Candida albicans is the secretion of aspartic proteases (Saps), which may contribute to colonization and infection of different host niches by degrading tissue barriers, destroying host defence molecules, or digesting proteins for nutrient supply. The role of individual Sap isoenzymes, which are encoded by a large gene family, for the pathogenicity of $C$. albicans has been investigated by assessing the virulence of mutants lacking specific SAP genes and by studying the expression pattern of the SAP genes in various models of superficial and systemic infections. We used a recombination-based genetic reporter system to detect the induction of the SAP1-SAP6 genes during infection of reconstituted human vaginal epithelium. Only $S A P 5$, but none of the other tested $S A P$ genes, was detectably activated in this in vitro infection model. To directly address the importance of the SAP1-SAP6 genes for invasion of reconstituted human epithelia (RHE), we constructed a set of mutants of the wild-type C. albicans model strain SC5314 in which either single or multiple SAP genes were specifically deleted. Even mutants lacking all of the SAP1-SAP3 or the SAP4SAP6 genes displayed the same capacity to invade and damage both oral and vaginal RHE as their wild-type parental strain, in contrast to a nonfilamentous efg $1 \Delta$ mutant that was avirulent under these conditions. We therefore conclude from these results that the secreted aspartic proteases Sap1p-Sap6p are not required for invasion of RHE by C. albicans.
\end{abstract}

\section{INTRODUCTION}

The yeast Candida albicans is a harmless commensal on mucosal surfaces of the gastrointestinal and urogenital tract in most healthy people. However, especially in immunocompromised patients, C. albicans can also invade into the epithelium and cause superficial as well as life-threatening disseminated infections (Odds, 1988). The secretion of aspartic proteases has long been recognized as a virulenceassociated trait of this fungal pathogen (Kwon-Chung et al., 1985; Macdonald \& Odds, 1983; Staib, 1969). C. albicans possesses a gene family encoding secreted aspartic proteases (Saps), which are thought to have different roles during an infection, e.g. the degradation of tissue barriers during invasion, destruction of host defence molecules, or nutrient supply (Naglik et al., 2003a). The importance of specific Sap isoenzymes for the pathogenicity of C. albicans has been investigated by comparing the virulence of mutants deleted for individual or multiple SAP genes with that of a wild-type control strain in different infection

Abbreviations: IVET, in vitro expression technology; LDH, lactate dehydrogenase; MPA, mycophenolic acid; RHE, reconstituted human epithelium/epithelia; Sap, secreted aspartic protease. models. Especially the SAP1-SAP6 genes have been studied extensively. Initially it was demonstrated that $\operatorname{sap} 1 \Delta$, sap $2 \Delta$ and sap $3 \Delta$ single mutants as well as triple mutants lacking the highly homologous SAP4-SAP6 genes exhibited attenuated virulence after intravenous infection of mice, indicating that all these genes have important roles for the normal progression of a systemic infection (Hube et al., 1997; Sanglard et al., 1997). Mutants deleted for either $S A P 1, S A P 2$ or SAP3 were also found to be less virulent in a rat model of Candida vaginitis, whereas mutants lacking SAP4-SAP6 did not exhibit a detectable virulence defect under these conditions (De Bernardis et al., 1999). Conversely, only the latter mutants showed reduced virulence in a murine model of Candida peritonitis, while deletion of SAP1, SAP2 or SAP3 had no significant effect in this infection model (Kretschmar et al., 1999). These and other studies indicate that the relative importance of specific SAP genes for the pathogenicity of C. albicans depends on the type of infection.

As the various Sap isoenzymes may have partially redundant functions, the analysis of deletion mutants might not reveal a role of a particular $S A P$ gene under all conditions. The individual members of the SAP gene family 
are differentially expressed during in vitro growth, depending on the cell type and the growth conditions (Hube et al., 1994; White \& Agabian, 1995). For example, SAP2 is specifically induced in media containing proteins as the sole nitrogen source and is required for growth of $C$. albicans under these conditions. SAP1 and SAP3 are phase-specific genes and are specifically expressed in opaque cells, the mating-competent form of C. albicans, while expression of SAP4-SAP6 is usually stimulated under conditions that promote hyphal growth. Assuming that the expression of a specific $S A P$ gene in a certain tissue reflects its role at that stage of an infection, various investigators have studied the expression patterns of the SAP genes in different types of infections. In an early study, expression of SAP1 and SAP2 during experimental vaginitis in rats could be demonstrated by Northern hybridization analysis (De Bernardis et al., 1995). Expression of SAP1, SAP2 and SAP4-SAP6 was detected by RT-PCR during invasion of parenchymal organs after intraperitoneal infection of mice (Felk et al., 2002). In a mouse model of oroesophageal and gastric candidiasis, all $S A P$ genes were detectably expressed during gastric candidiasis, while SAP1 and SAP3 were only sporadically and weakly expressed at different oral sites of infection (Schofield et al., 2003). Several investigators have also used RT-PCR to analyse the expression of specific SAP genes during colonization and infection of humans. Schaller et al. (1998) detected SAP1-SAP3 and SAP6 transcripts in samples from patients with oral candidiasis, whereas no expression of SAP4 and SAP5 was found. In contrast, Naglik et al. (2003b) found SAP2 and SAP5 to be the most commonly expressed genes in individuals with oral and vaginal Candida carriage or infection, while SAP1 and SAP3 were preferentially expressed in vaginal, rather than oral, infections.

In vitro models using reconstituted human epithelia (RHE) have also been used to evaluate the importance of specific Sap isoenzymes for tissue invasion and to investigate the expression patterns of individual $S A P$ genes. On oral RHE, expression of SAP1-SAP3 and SAP6, but not SAP4 and SAP5, was detected by RT-PCR and each of the SAP1-SAP3 genes was also found to be required for wild-type levels of tissue damage in this model (Schaller et al., 1998, 1999). SAP1 and SAP2, but not SAP3-SAP6, were also required for tissue damage during infection of vaginal RHE, although RT-PCR showed almost all of these SAP genes to be expressed under these conditions (Schaller et al., 2003). A role of the Saps during infection of RHE was also demonstrated by the observation that the extent of tissue damage caused by the wild-type strain SC5314 was reduced in the presence of aspartic protease inhibitors (Schaller et al., 1999, 2003).

While all of the above studies point to a differential expression and specific roles of the various SAP genes during colonization and infection of different host tissues, there are also discrepancies in the results obtained, which may be related to differences in the sensitivities of the methods used in various laboratories, intrinsic differences even in apparently similar infection models, and variability among different $C$. albicans strains.
Our group has previously employed a genetic reporter system, termed in vivo expression technology (IVET), to study the expression of the SAP1-SAP6 genes in the C. albicans model strain SC5314 during experimental infections. We constructed a set of reporter strains which carry a Candida-adapted FLP gene (ecaFLP), encoding the sitespecific recombinase FLP, under control of the various SAP gene promoters. The induction of the promoter results in expression of the FLP recombinase, which in turn catalyses the excision of a mycophenolic acid resistance marker $\left(M P A^{R}\right)$ from the genome, so that even a transient induction of the target gene during an infection can be detected in individual cells by the MPA-sensitive phenotype of their progeny after reisolation from infected tissue (Staib et al., 1999). Using this reporter system we could also detect a stage- and tissue-specific expression pattern of the SAP1-SAP6 genes. We found that SAP5 was induced at an early stage in all infection models examined (intravenous, intraperitoneal, oral and vaginal infections of mice), whereas other SAP genes had a more specific expression pattern. Beside its activation after intravenous infection, SAP6 expression was detected during invasion of the oesophageal mucosa, but not in a mouse model of vaginal candidiasis. Conversely, SAP4 was significantly expressed during vaginal, but not oesophageal infection. SAP2 expression was usually found at the late stages of intraperitoneal and systemic infections, although the SAP2-2 allele was also induced at earlier time points. No significant expression of SAP2 or the opaque-specific SAP1 and SAP3 genes was observed during infection of the oesophageal or vaginal tissue of mice (Staib et al., 2000, 2002a; Taylor et al., 2005). Especially the latter results were in striking contrast to findings of other researchers, who found SAP1-SAP3 to be expressed during oral and/or vaginal infections of rats and humans and, in contrast to the SAP4-SAP6 genes, also to be required for invasion of oral and vaginal RHE (see above). Although the results obtained with the ecaFLP reporter gene in the mouse model of vaginal candidiasis were fully confirmed using green fluorescent protein (GFP) as an alternative reporter (Taylor et al., 2005), it remained possible that both reporter systems were not sensitive enough to detect a low but biologically relevant expression of the SAP1-SAP3 genes. Alternatively, it seemed possible that the environment encountered during vaginal infection in mice is different from that to which C. albicans is exposed during human and rat vaginitis and also during in vitro infection of RHE. To address these issues, we used the reportedly highly reproducible oral and vaginal RHE infection models (Naglik et al., 2003a) to re-examine both the expression pattern and the importance of the SAP1-SAP6 genes for epithelial invasion and damage by C. albicans.

\section{METHODS}

Strains and growth conditions. C. albicans strains used in this study and, for clarity, the relevant parent strains are listed in Table 1. All strains were stored as frozen stocks with $15 \%$ glycerol at $-80{ }^{\circ} \mathrm{C}$. 
Table 1. C. albicans strains

\begin{tabular}{|c|c|c|c|}
\hline Strain & Parent & Relevant characteristics or genotype ${ }^{\star}$ & Reference \\
\hline SC5314 & & Prototrophic wild-type strain & Gillum et al. (1984) \\
\hline CAI4 & SC5314 & ura3s:: imm434/ura3s : : imm 434 & Fonzi \& Irwin (1993) \\
\hline Can33 & CAI4 & efg1:: hisG/efg1:: hisG-URA3-hisG & Dieterich et al. (2002) \\
\hline \multicolumn{4}{|l|}{ Reporter strains } \\
\hline S1FI2A & CFI1 & SAP1-1/sap1-2:: $\mathrm{P}_{S A P 1}-e c a F L P-U R A 3$ & Staib et al. (2000) \\
\hline S2FI5B & CFI1 & sap2-1:: $\mathrm{P}_{\text {SAP2-1 }}$-ecaFLP-URA3/SAP2-2 & Staib et al. (2000) \\
\hline S2FI7A & CFI1 & SAP2-1/sap2-2:: $\mathrm{P}_{S A P 2-2}-e c a F L P-U R A 3$ & Staib et al. (2002a) \\
\hline S3FI2B & CFI1 & SAP3/sap $3:: \mathrm{P}_{\text {SAP3 } \text {-ecaFLP-URA3 }}$ & Staib et al. (2000) \\
\hline S3FI2C & CFI1 & SAP3/sap3: : $\mathrm{P}_{S A P 3}-e c a F L P-U R A 3$ & Staib et al. (2000) \\
\hline S4FI2A & CFI1 & SAP4-1/sap4-2:: $\mathrm{P}_{S A P 4}$-ecaFLP-URA3 & Staib et al. (2000) \\
\hline S4FI2B & CFI1 & sap4-1:: $\mathrm{P}_{S A P 4}-$ ecaFLP-URA3/SAP4-2 & Staib et al. (2000) \\
\hline S2UI1A & CFI1 & sap2-1:: URA3/SAP2-2 & Staib et al. (1999) \\
\hline \multicolumn{4}{|l|}{ sap1 $1 \Delta$ single mutants } \\
\hline SAP1MS1A & SC5314 & sap1-1D: : SAT1-FLIP $\dagger / S A P 1-2$ & This study \\
\hline SAP1MS1B & SC5314 & SAP1-1/sap1-2D:: SAT1-FLIP & This study \\
\hline SAP1MS2A & SAP1MS1A & sap1-1A:: FRT/SAP1-2 & This study \\
\hline SAP1MS2B & SAP1MS1B & SAP1-1/sap1-2A::FRT & This study \\
\hline SAP1MS3A & SAP1MS2A & 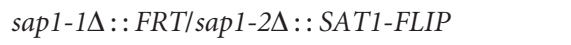 & This study \\
\hline SAP1MS3B & SAP1MS2B & 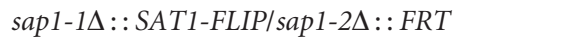 & This study \\
\hline SAP1MS4A & SAP1MS3A & sap1-1 $1:: F R T / \operatorname{sap} 1-2 \Delta:: F R T$ & This study \\
\hline SAP1MS4B & SAP1MS3B & 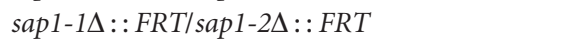 & This study \\
\hline \multicolumn{4}{|l|}{ sap $2 \Delta$ single mutants } \\
\hline SAP3MS4A & SAP3MS3A & $\operatorname{sap} 3 \Delta:: F R T / \operatorname{sap} 3 \Delta:: F R T$ & This study \\
\hline SAP3MS4B & SAP3MS3B & $\operatorname{sap} 3 \Delta:: F R T / \operatorname{sap} 3 \Delta:: F R T$ & This study \\
\hline \multicolumn{4}{|l|}{ sap $4 \Delta$ single mutants } \\
\hline SAP4MS1A & SC5314 & sap4-1A:: SAT1-FLIP/SAP4-2 & This study \\
\hline SAP4MS1B & SC5314 & SAP4-1/sap4-2A : :SAT1-FLIP & This study \\
\hline SAP4MS2A & SAP4MS1A & sap4-1A:: FRT/SAP4-2 & This study \\
\hline SAP4MS2B & SAP4MS1B & SAP4-1/sap4-2A::FRT & This study \\
\hline SAP4MS3A & SAP4MS2A & 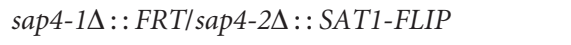 & This study \\
\hline SAP4MS3B & SAP4MS2B & 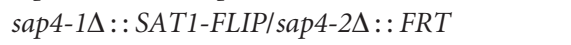 & This study \\
\hline SAP4MS4A & SAP4MS3A & 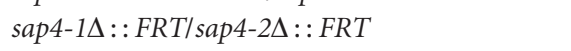 & This study \\
\hline SAP4MS4B & SAP4MS3B & 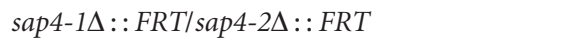 & This study \\
\hline \multicolumn{4}{|l|}{ sap5 $\Delta$ single mutants } \\
\hline SAP5MS1A & SC5314 & sap5-1A: : SAT1-FLIP/SAP5-2 & This study \\
\hline SAP5MS1B & SC5314 & SAP5-1/sap5-2A:: SAT1-FLIP & This study \\
\hline SAP5MS2A & SAP5MS1A & sap5-1A:: FRT/SAP5-2 & This study \\
\hline SAP5MS2B & SAP5MS1B & SAP5-1/sap5-2A::FRT & This study \\
\hline SAP5MS3A & SAP5MS2A & 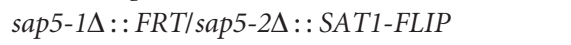 & This study \\
\hline SAP5MS3B & SAP5MS2B & 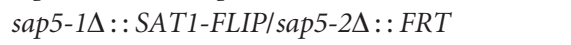 & This study \\
\hline SAP5MS4A & SAP5MS3A & 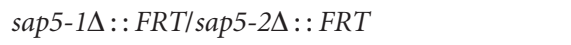 & This study \\
\hline SAP5MS4B & SAP5MS3B & 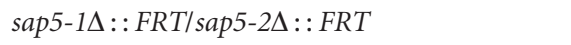 & This study \\
\hline \multicolumn{4}{|l|}{ sap6 $\Delta$ single mutants } \\
\hline SAP6MS1A & SC5314 & sap6-1A:: SAT1-FLIP/SAP6-2 & This study \\
\hline
\end{tabular}


Table 1. cont.

\begin{tabular}{|c|c|c|c|}
\hline Strain & Parent & Relevant characteristics or genotype ${ }^{\star}$ & Reference \\
\hline SAP6MS1B & SC5314 & SAP6-1/sap6-2D:: SAT1-FLIP & This study \\
\hline SAP6MS2A & SAP6MS1A & sap6-1A:: FRT/SAP6-2 & This study \\
\hline SAP6MS2B & SAP6MS1B & SAP6-1/sap6-2A::FRT & This study \\
\hline SAP6MS3A & SAP6MS2A & 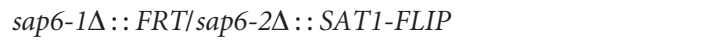 & This study \\
\hline SAP6MS3B & SAP6MS2B & sap6-1D:: SAT1-FLIP/sap6-2A:: FRT & This study \\
\hline SAP6MS4A & SAP6MS3A & 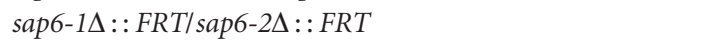 & This study \\
\hline SAP6MS4B & SAP6MS3B & 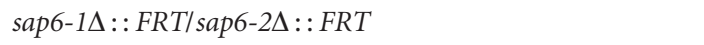 & This study \\
\hline \multicolumn{4}{|c|}{ sap1 $1 \Delta$ sap $2 \Delta$ double mutants } \\
\hline SAP12MS1A & SAP2MS4A & 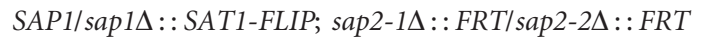 & This study \\
\hline SAP12MS1B & SAP2MS4B & 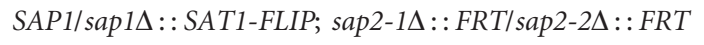 & This study \\
\hline SAP12MS2A & SAP12MS1A & 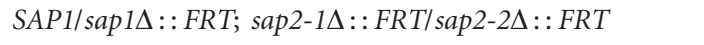 & This study \\
\hline SAP12MS2B & SAP12MS1B & 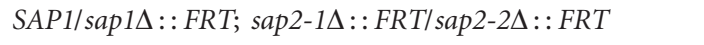 & This study \\
\hline SAP12MS3A & SAP12MS2A & $\begin{array}{l}\text { sap } 1 \Delta:: \text { SAT1-FLIP/sap1 } 1 \Delta:: F R T ; \text { sap2-1 } 1 \Delta: \text { FRT/sap2- } \\
2 \Delta:: F R T\end{array}$ & This study \\
\hline SAP12MS3B & SAP12MS2B & $\begin{array}{l}\text { sap } 1 \Delta:: S A T 1-F L I P / \operatorname{sap} 1 \Delta:: F R T ; \text { sap2-1 } 1 \Delta:: F R T / \text { sap2- } \\
2 \Delta:: F R T\end{array}$ & This study \\
\hline SAP12MS4A & SAP12MS3A & 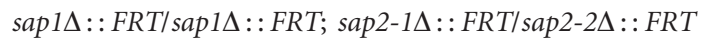 & This study \\
\hline SAP12MS4B & SAP12MS3B & 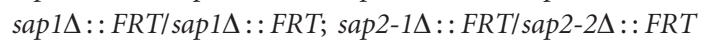 & This study \\
\hline \multicolumn{4}{|c|}{$\operatorname{sap} 1 \Delta \operatorname{sap} 3 \Delta$ double mutants } \\
\hline SAP13MS1A & SAP1MS4A & 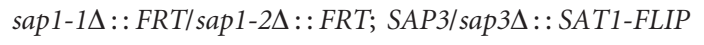 & This study \\
\hline SAP13MS1B & SAP1MS4B & 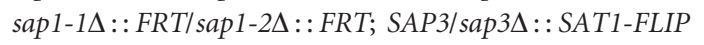 & This study \\
\hline SAP13MS2A & SAP13MS1A & 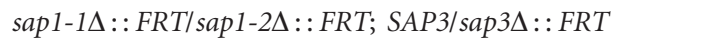 & This study \\
\hline SAP13MS2B & SAP13MS1B & 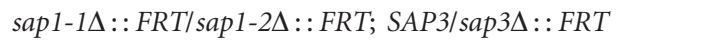 & This study \\
\hline SAP13MS3A & SAP13MS2A & $\begin{array}{l}\operatorname{sap} 1-1 \Delta:: F R T / \operatorname{sap} 1-2 \Delta:: F R T ; \operatorname{sap} 3 \Delta:: \text { SAT1-FLIP/ } \\
\text { sap3 }:: \text { FRT }\end{array}$ & This study \\
\hline SAP13MS3B & SAP13MS2B & $\begin{array}{l}\text { sap1-1 } 1:: F R T / \operatorname{sap} 1-2 \Delta:: F R T ; \text { sap } 3 \Delta:: S A T 1-F L I P / \\
\text { sap } 3 \Delta:: F R T\end{array}$ & This study \\
\hline SAP13MS4A & SAP13MS3A & 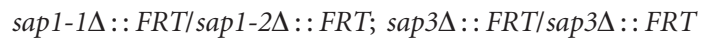 & This study \\
\hline SAP13MS4B & SAP13MS3B & 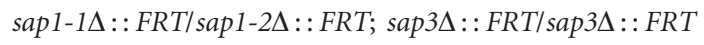 & This study \\
\hline \multicolumn{4}{|c|}{$\operatorname{sap} 2 \Delta \operatorname{sap} 3 \Delta$ double mutants } \\
\hline SAP23MS1C & SAP3MS4A & 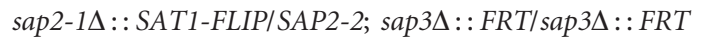 & This study \\
\hline SAP23MS1D & SAP3MS4B & 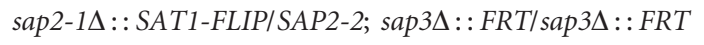 & This study \\
\hline SAP23MS2C & SAP23MS1C & sap2-1 $1 \Delta:: F R T / S A P 2-2 ; \operatorname{sap} 3 \Delta:: F R T / \operatorname{sap} 3 \Delta:: F R T$ & This study \\
\hline SAP23MS2D & SAP23MS1D & sap2-1 $\Delta::$ FRT/SAP2-2; sap3 $\Delta:: F R T / \operatorname{sap} 3 \Delta:: F R T$ & This study \\
\hline SAP23MS3C & SAP23MS2C & $\begin{array}{l}\operatorname{sap} 2-1 \Delta:: F R T / \operatorname{sap} 2-2 \Delta:: S A T 1-F L I P ; \operatorname{sap} 3 \Delta:: F R T / \\
\operatorname{sap} 3 \Delta:: F R T\end{array}$ & This study \\
\hline SAP23MS3D & SAP23MS2D & $\begin{array}{l}\operatorname{sap} 2-1 \Delta:: F R T / \operatorname{sap} 2-2 \Delta:: S A T 1-F L I P ; \operatorname{sap} 3 \Delta:: F R T / \\
\operatorname{sap} 3 \Delta:: F R T\end{array}$ & This study \\
\hline SAP23MS4C & SAP23MS3C & 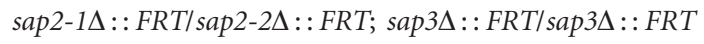 & This study \\
\hline SAP23MS4D & SAP23MS3D & 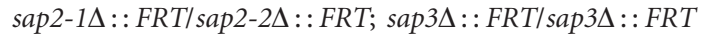 & This study \\
\hline \multicolumn{4}{|c|}{ 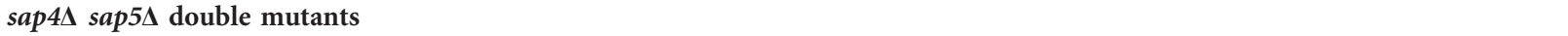 } \\
\hline SAP45MS1A & SAP4MS4A & 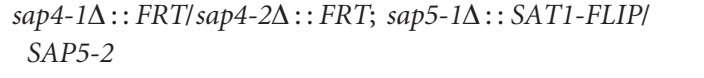 & This study \\
\hline SAP45MS1B & SAP4MS4B & 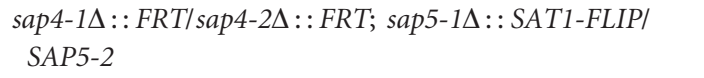 & This study \\
\hline SAP45MS2A & SAP45MS1A & 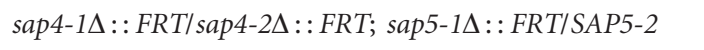 & This study \\
\hline SAP45MS2B & SAP45MS1B & 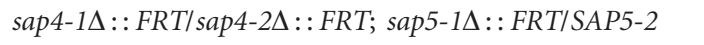 & This study \\
\hline SAP45MS3A & SAP45MS2A & 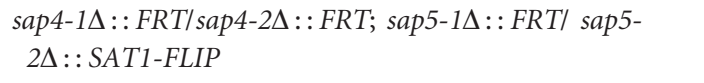 & This study \\
\hline SAP45MS3B & SAP45MS2B & 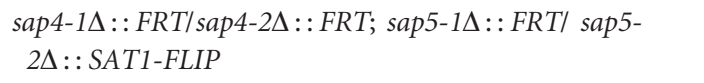 & This study \\
\hline SAP45MS4A & SAP45MS3A & 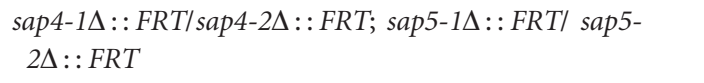 & This study \\
\hline SAP45MS4B & SAP45MS3B & 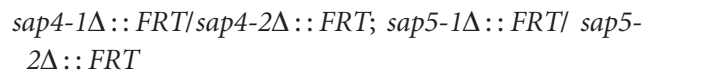 & This study \\
\hline
\end{tabular}


Table 1. cont.

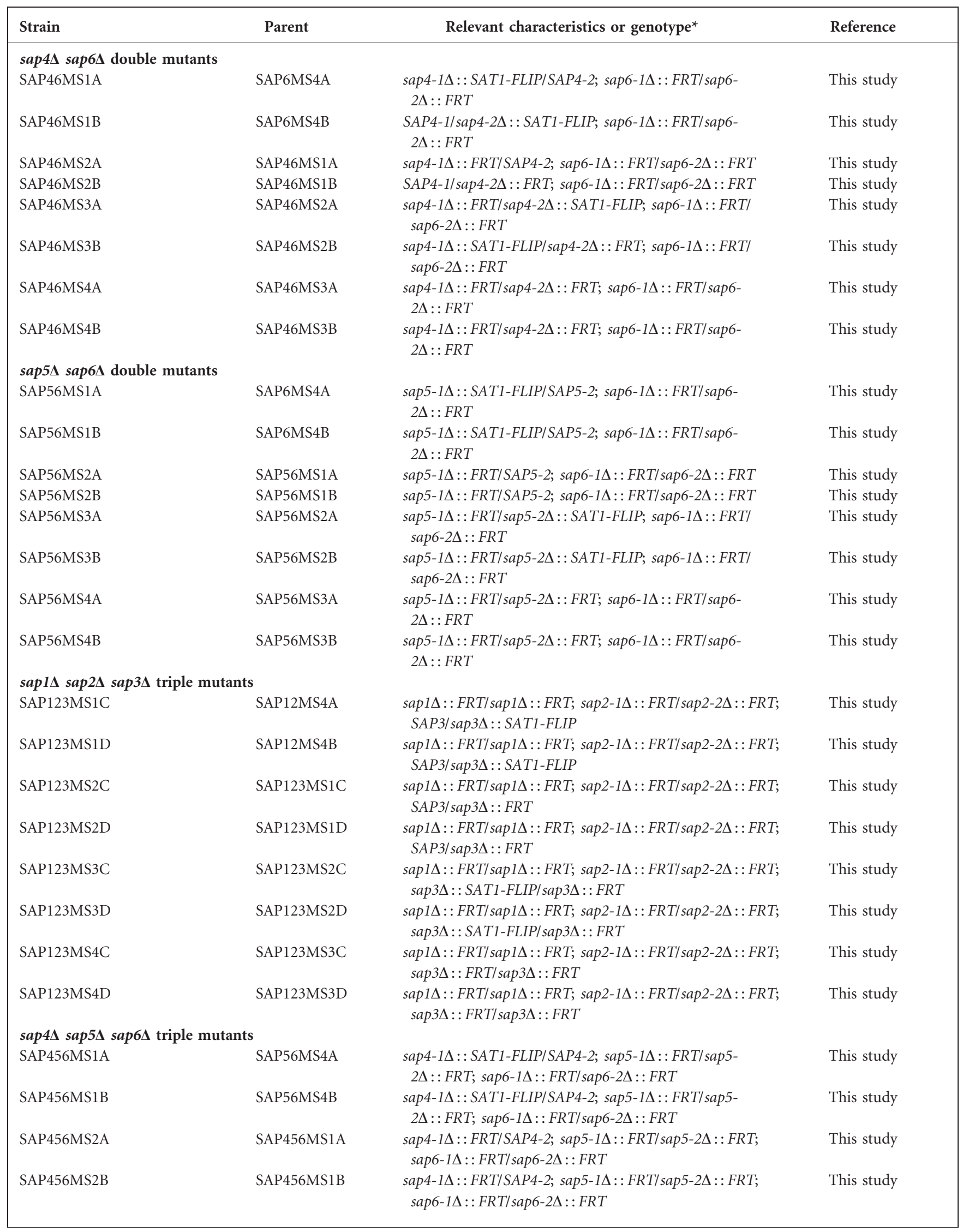


Table 1. cont.

\begin{tabular}{|c|c|c|c|}
\hline Strain & Parent & Relevant characteristics or genotype ${ }^{\star}$ & Reference \\
\hline SAP456MS3A & SAP456MS2A & 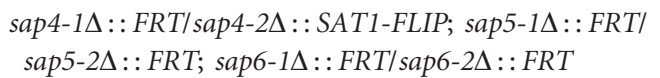 & This study \\
\hline SAP456MS3B & SAP456MS2B & 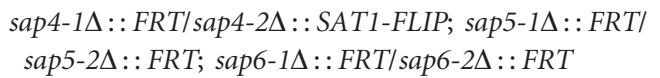 & This study \\
\hline SAP456MS4A & SAP456MS3A & 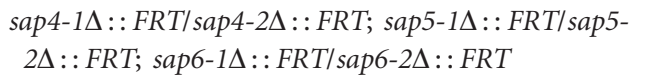 & This study \\
\hline SAP456MS3B & SAP456MS3B & 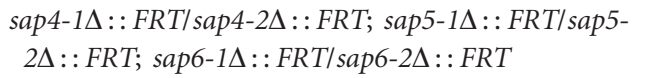 & This study \\
\hline
\end{tabular}

*Apart from the indicated features all strains are identical to their parental strains.

$\dagger$ SAT1-FLIP denotes the SAT1 flipper cassette. In strain SC5314, the two SAP1 alleles can be distinguished by a KpnI restriction fragment length polymorphism (RFLP), the two SAP2 alleles by a ClaI RFLP, the two SAP4 and the two SAP5 alleles by a BgIII RFLP, and the two SAP6 alleles by an EcoRI RFLP. In those cases in which we determined which of the two alleles was inactivated first, the alleles are distinguished by a suffix.

The strains were routinely grown in YPD medium $[10 \mathrm{~g}$ yeast extract, $20 \mathrm{~g}$ peptone (BBL Trypticase Peptone, Becton Dickinson) and $20 \mathrm{~g}$ glucose per litre] at $30{ }^{\circ} \mathrm{C}$. Reporter strains were grown in SD medium [6.7 g yeast nitrogen base without amino acids (YNB; Bio 101) and $20 \mathrm{~g}$ glucose per litre]. To prepare solid media, $1.5 \%$ agar was added before autoclaving. For excision of the SAT1 flipper from nourseothricin-resistant transformants by FLP-mediated recombination, the strains were cultivated overnight in YPM medium (10 g yeast extract, $20 \mathrm{~g}$ peptone and $20 \mathrm{~g}$ maltose per litre) without selective pressure to induce the MAL2 promoter. One hundred to two hundred cells were spread on YPD plates containing $20 \mu \mathrm{g}$ nourseothricin $\mathrm{ml}^{-1}$ (Werner Bioagents) and grown for 2 days at $30^{\circ} \mathrm{C}$. Nou ${ }^{\mathrm{S}}$ clones were identified by their small colony size and confirmed by restreaking on YPD plates containing $100 \mu \mathrm{g}$ nourseothricin $\mathrm{ml}^{-1}$ as described previously (Reuß et al., 2004). To test for growth on BSA as the sole nitrogen source, strains were grown at $30{ }^{\circ} \mathrm{C}$ or $37^{\circ} \mathrm{C}$ in YCB-BSA medium $[23.4 \mathrm{~g}$ yeast carbon base, $4 \mathrm{~g}$ bovine serum albumin (Fraction V; Gerbu) per litre, $\mathrm{pH} 4.0]$.

Plasmid constructions. Plasmid pSAP2MS2, which was used to delete the SAP2 gene, has been described before (Staib et al., 2008). Analogous constructs were generated for the deletion of $S A P 1$ and SAP3-SAP6. ApaI-SalI fragments containing the upstream sequences of these genes were obtained from plasmids pSFL13, pSFL33, pSFL43, pSFL53 and pSFL63 (Staib et al., 2000) and ligated into ApaI/XhoIdigested pOPT1M3 (Reuß et al., 2004), resulting in plasmids pSAP1MS1, pSAP3MS1, pSAP4MS1, pSAP5MS1 and pSAP6MS1, respectively. The downstream regions of the SAP genes were then amplified using the primer pairs SAP1K/SAP1L, SAP3K/SAP3L, SAP4K/SAP4L, SAP5N/SAP5Q and SAP6N/SAP6Q (primer sequences are given in Table 2). The PCR products were digested at the introduced SacII and SacI sites and ligated between the same sites of the plasmids described above, resulting in pSAP1MS2, pSAP3MS2, pSAP4MS2, pSAP5MS2 and pSAP6MS2 (see Fig. 2a and c, Fig. 3a-c).

C. albicans transformation. C. albicans strain SC5314 was transformed by electroporation (Köhler et al., 1997) with the gel-purified ApaI-SacI fragments from plasmids pSAP1MS2, pSAP2MS2, pSAP3MS2, pSAP4MS2, pSAP5MS2 and pSAP6MS2. Nourseothricinresistant transformants were selected on YPD agar plates containing $200 \mu \mathrm{g}$ nourseothricin $\mathrm{ml}^{-1}$ as described previously (Reuß et al., 2004). Single-copy integration of all constructs was confirmed by Southern hybridization.

Isolation of genomic DNA and Southern hybridization. Genomic DNA from C. albicans strains was isolated as described previously
(Millon et al., 1994). A $10 \mu \mathrm{g}$ sample of DNA was digested with appropriate restriction enzymes, separated on a $1 \%$ agarose gel and, after ethidium bromide staining, transferred by vacuum blotting onto a nylon membrane and fixed by UV cross-linking. Southern hybridization with enhanced chemiluminescence-labelled probes was performed with the Amersham ECL Direct Nucleic Acid Labelling and Detection System (GE Healthcare) according to the instructions of the manufacturer.

Cultivation of reconstituted human epithelia. The human epithelia for the in vitro model of oral and vaginal candidiasis were supplied by SkinEthic Laboratories. Oral and vaginal RHE were obtained by culturing the human cell lines TR146 and A431, respectively, on an inert supporting membrane. According to the guidelines of the supplier, uninfected and infected RHE were incubated in $1 \mathrm{ml}$ SkinEthic maintenance medium at $37{ }^{\circ} \mathrm{C}$ with $5 \% \mathrm{CO}_{2}$ at $100 \%$ humidity. After $24 \mathrm{~h}$, the culture medium was removed and fresh medium was added.

Detection of SAP induction during infection of vaginal RHE. Reporter strains were grown overnight at $30{ }^{\circ} \mathrm{C}$ in SD medium, washed, and resuspended in PBS at a density of $10^{7}$ cells $\mathrm{ml}^{-1}$. Vaginal RHE was infected with $5 \times 10^{5}$ C. albicans cells. After $48 \mathrm{~h}$ of incubation, the RHE was lysed by the addition of sterile distilled water and the C. albicans cells were recovered and plated at an appropriate density on indicator plates (SD agar containing $1.8 \mu \mathrm{g} \mathrm{MPA} \mathrm{ml}{ }^{-1}$ ).

Table 2. Primers used in this study

Restriction sites introduced into the primers are underlined.

\begin{tabular}{|ll|}
\hline Primer & \multicolumn{1}{c|}{ Sequence $\left(\mathbf{3}^{\prime} \mathbf{-} \mathbf{5}^{\prime}\right)$} \\
\hline SAP1K & GAGATACCTACTTCCGCGGTTATAAGTGTC \\
SAP1L & TCCAAGAGCTCAAGTAGCTTTCCAAC \\
SAP3K & GCTGCTCTTACCGCGGGGGAAGTACAC \\
SAP3L & CCAATTGAATTAGAGCTCTTTTTACCAGCC \\
SAP4K & GACGACCGCGGTTTTAGATTAATTGTCGG \\
SAP4L & GGTGTAATTGCTGAGCTCTTTTTGATGG \\
SAP5N & ATTAACCGCGGACTTTGACTTTAGATTAATTATC \\
SAP5Q & TAAGTGAGCTCATGATTTTGTTGTATCTATGG \\
SAP6N & GAAAACCGCGGTTTTAGATTAATTATCGATTTGC \\
SAP6Q & GAAACTGCGTGAGCTCTCACATTGCACG \\
\hline
\end{tabular}


The percentage of small colonies was determined after 2 days of growth at $30{ }^{\circ} \mathrm{C}$. C. albicans cells from the precultures were also plated on the MPA indicator plates to verify that no promoter induction had occurred before the infection.

Light microscopy. Oral or vaginal RHE was infected as described above with $C$. albicans strains grown overnight at $30{ }^{\circ} \mathrm{C}$ in YPD medium. In some experiments, pepstatin A (Sigma) was added at a final concentration of $15 \mu \mathrm{M}$. After $48 \mathrm{~h}$ of incubation, the RHE was fixed with $2.5 \%$ glutaraldehyde and $2 \%$ formaldehyde in a $0.05 \mathrm{M}$ cacodylate-buffered solution ( $\mathrm{pH} 7.2)$ at room temperature. After several washing and dehydration steps with chilled solutions, the tissues were embedded in glycide ether. Semi-thin sections $(300 \mathrm{~nm})$ of the embedded tissues were obtained by using an RMC MT 7000 ultramicrotome, stained with $0.5 \%$ methylene blue and $0.5 \%$ azur II, and observed by light microscopy.

Determination of LDH activity. The release of lactate dehydrogenase (LDH) from infected epithelial cells into the surrounding medium was monitored as a measure of tissue damage. LDH activity was determined with the CytoTox 96 non-radioactive cytotoxicity assay (Promega) according to the instructions of the manufacturer. Controls consisted of uninfected RHE (target spontaneous) and C. albicans cells grown in culture medium without RHE (effector spontaneous). Total LDH activity in the epithelial cells was determined after complete lysis of an uninfected sample with the lysis buffer provided in the kit (target maximum). After subtracting the absorbance values of the culture medium, tissue damage caused by $C$. albicans was calculated according to the following formula: $\%$ tissue damage $=($ experimental - effector spontaneous - target spontaneous)/(target maximum - target spontaneous).

\section{RESULTS}

\section{Expression pattern of the SAP1-SAP6 genes on reconstituted human vaginal epithelium}

To investigate the expression of the SAP1-SAP6 genes during infection of vaginal RHE, we used a set of reporter strains expressing ecaFLP under control of the respective SAP gene promoters (see Table 1). Vaginal RHE was infected with each of the reporter strains as well as with a similarly constructed control strain that does not contain the ecaFLP gene and, therefore, stably retains the $M P A^{R}$ marker in the genome. $C$. albicans cells were recovered after $48 \mathrm{~h}$ of infection, appropriately diluted, and spread on MPA-containing indicator plates to determine the percentage of small colonies, which are generated from cells that have lost the $M P A^{R}$ marker by FLP-mediated recombination. As can be seen in Fig. 1, only the SAP5 promoter was significantly activated under these conditions, whereas the other reporter strains generated only a few small colonies, similar to the control strain, which produced a background of about $3 \%$ small colonies due to accidental slower growth, which is in agreement with previously reported values in other infection models (Staib et al., 1999). The SAP gene expression pattern observed in this in vitro model of vaginal infection partially corresponds to previous results obtained with the same set of reporter strains in a mouse model of vaginal candidiasis, in that no significant expression of SAP1-SAP3 and SAP6 was detected and SAP5 was induced in both models. However, in the in vivo model SAP4 was also expressed in addition to SAP5, albeit at lower levels (Taylor et al., 2005), while this was not the case in the in vitro model. In addition, while SAP5 expression was detected in virtually all infecting cells in the mouse model, only about $20 \%$ of the cells had detectably activated the SAP5 promoter in the RHE model (see Fig. 1). These results indicated that the signals inducing SAP5 (and SAP4) expression during vaginal infection in mice are stronger than those that result in SAP5 activation during in vitro infection of the RHE.

\section{Construction of mutants of the $C$. albicans wild- type strain SC5314 lacking individual or multiple SAP genes}

The SAP gene expression pattern observed during infection of the vaginal RHE with our reporter strains is in striking contrast to the results obtained by other researchers, who detected expression of SAP1, SAP2 and SAP4-6 in the same model by RT-PCR. These researchers also found that tissue damage was drastically reduced in mutants lacking either $S A P 1$ or SAP2, implying an important role of these genes for invasion of the vaginal epithelium (Schaller et al., 2003). Although we had previously shown that the activation of the SAP2 promoter under known inducing

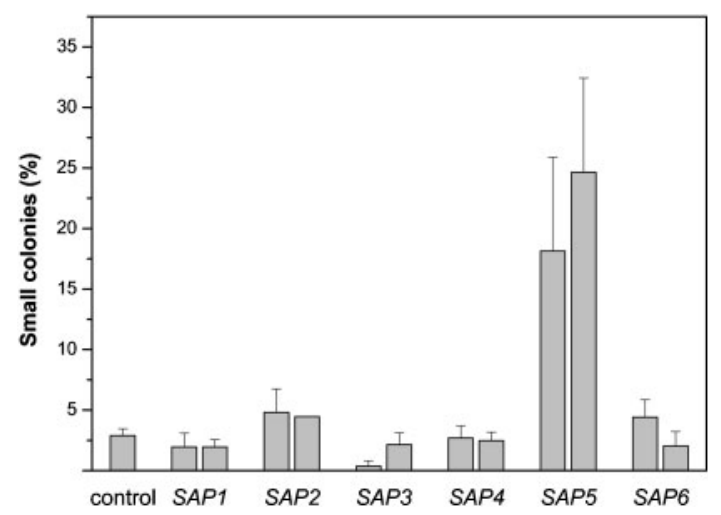

Fig. 1. Induction of the SAP1-SAP6 promoters during invasion of vaginal RHE. Reporter strains expressing the ecaFLP gene under control of the indicated SAP gene promoters were used to infect vaginal RHE. C. albicans cells were recovered after $48 \mathrm{~h}$ of incubation and plated on MPA indicator plates. The percentage of small colonies was determined after 2 days of growth at $30{ }^{\circ} \mathrm{C}$. For each SAP gene, two independently constructed reporter strains were used (see Table 1). Results are the means \pm SD from two to four experiments, except for the SAP2 reporter strain S2FI7A (second SAP2 column), where the value is from a single experiment because in the other experiments too many cells had lost the $M P A^{R}$ marker already in the preculture due to basal activity of the SAP2-2 promoter. Strain S2Ul1A, which does not contain the ecaFLP gene, was used as a control to estimate the background of small colonies appearing as a result of accidental slow growth instead of excision of the $M P A^{R}$ marker. 

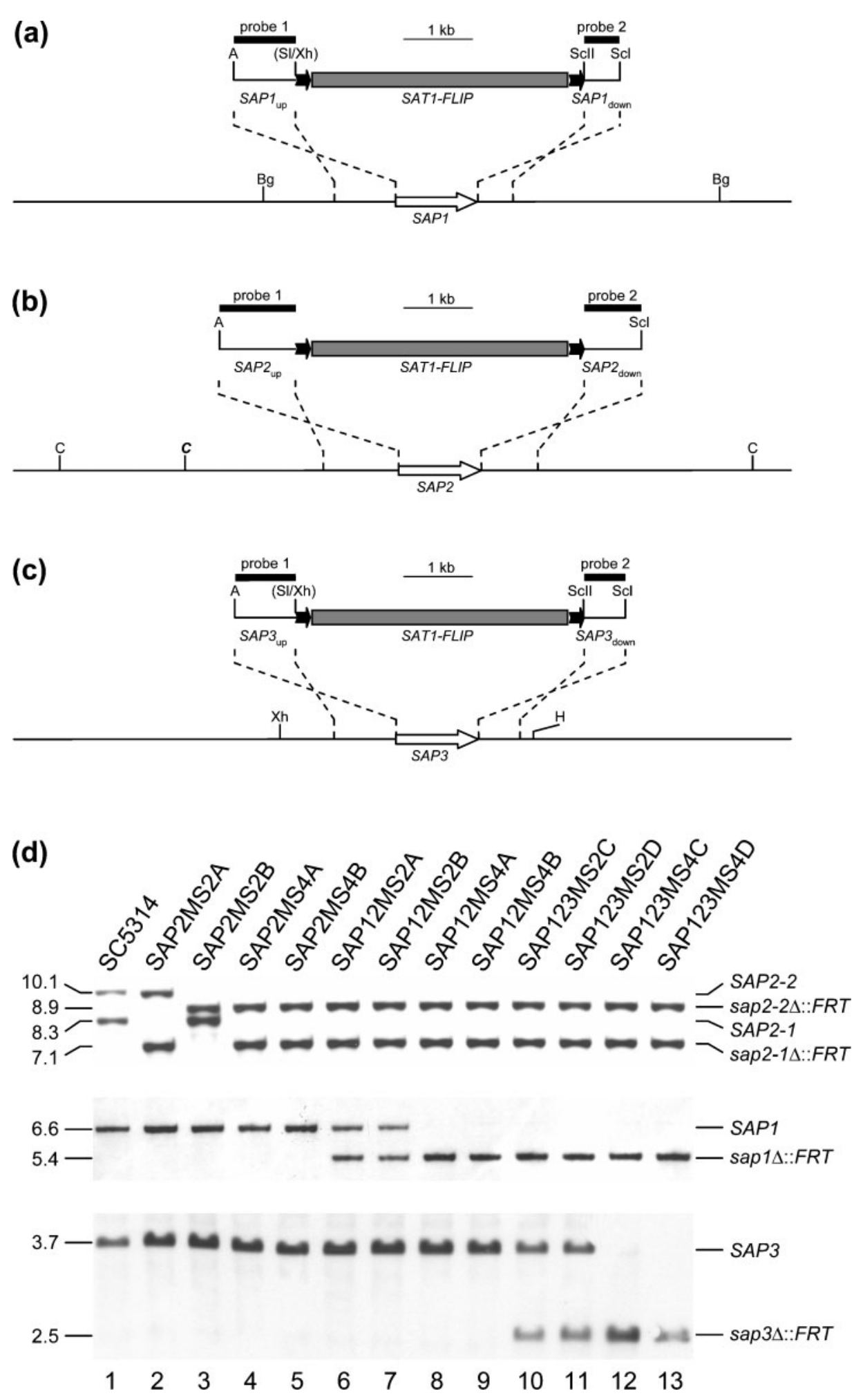

conditions in vitro could easily be detected with the ecaFLP reporter gene in all cells of the population (Staib et al., 2000, 2002a), we could not exclude the possibility that $S A P 2$ and other SAP genes are induced during RHE infection at low, but biologically relevant levels that are below the sensitivity limit of the reporter system. We therefore decided to readdress the importance of each of the SAP1-SAP6 genes for infection of RHE by assessing the virulence of mutants lacking specific $S A P$ genes in these models. The sap mutants used in earlier studies were generated from the auxotrophic laboratory strain CAI4 using the Ura-blaster protocol (Hube et al., 1997; Sanglard 
Fig. 2. Construction of sap $1 \Delta$ sap2 $\Delta$ sap3 $\Delta$ triple mutants. (a-c) Structure of the deletion cassettes from plasmids pSAP1MS2 (a), pSAP2MS2 (b) and pSAP3MS2 (c), which were used to delete the SAP1, SAP2 and SAP3 alleles, respectively, and genomic structure of the wild-type loci in strain SC5314. The SAP1-SAP3 coding regions are represented by white arrows and the upstream and downstream regions by the solid lines. Details of the SAT1 flipper cassette [grey rectangle bordered by FRT sites (black arrows)] have been presented elsewhere (Reuß et al., 2004). The 34 bp FRT sites are not drawn to scale. The probes used for Southern hybridization analysis of the mutants are indicated by the black bars. Only relevant restriction sites are given: A, Apal; Bg, Bgll; C, Clal; H, Hindlll; Scl, Sacl; Scll, Sacll; Sl, Sall; Xh, Xhol. Sites shown in parentheses were destroyed by the cloning procedure. The Clal site in bold italic is present only in the SAP2-1 allele. (d) Southern hybridizations of Clal- (for SAP2), Bg/ll- (for SAP1) and Xhol/Hindlll- (for SAP3) digested genomic DNA of the parental strain SC5314 and the indicated mutants with the SAP2-specific probe 1 (top), the SAP1-specific probe 1 (middle) and the SAP3-specific probe 1 (bottom). Lane 1, wild-type; lanes 2 and 3, SAP2/sap2 $\Delta$; lanes 4 and 5, sap2 $\Delta / \operatorname{sap} 2 \Delta$; lanes 6 and $7, S A P 1 / \operatorname{sap} 1 \Delta \operatorname{sap} 2 \Delta / \operatorname{sap} 2 \Delta$; lanes 8 and 9, sap1 $\Delta / \operatorname{sap} 1 \Delta \operatorname{sap} 2 \Delta / \operatorname{sap} 2 \Delta$; lanes 10 and 11 , sap $1 \Delta / \operatorname{sap} 1 \Delta \operatorname{sap} 2 \Delta / \operatorname{sap} 2 \Delta$ $S A P 3 / \operatorname{sap} 3 \Delta$; lanes 12 and $13, \operatorname{sap} 1 \Delta / \operatorname{sap} 1 \Delta \operatorname{sap} 2 \Delta / \operatorname{sap} 2 \Delta \operatorname{sap} 3 \Delta / \operatorname{sap} 3 \Delta$. The sizes of the hybridizing fragments (in $\mathrm{kb}) \operatorname{are}$ given on the left side of the blots and their identities are indicated on the right.

et al., 1997). As the use of the URA3 marker for mutant construction in C. albicans can sometimes cause problems in the interpretation of mutant phenotypes (Bain et al., 2001; Brand et al., 2004; Cheng et al., 2003; Lay et al., 1998; Sharkey et al., 2005), we constructed a new set of sap mutants from the prototrophic wild-type model strain SC5314 using the SAT1-flipping strategy (Reuß et al., 2004). For each of the SAP1-SAP6 genes, two independent series of homozygous deletion mutants were generated. In addition, within the SAP1-SAP3 and SAP4-SAP6 subgroups, we constructed two series of all possible double and triple mutants, starting from two independent single mutants. The generation of each mutant from its progenitors can be followed in Table 1, in which all strains are described, and the construction of the triple mutants is illustrated and documented in Figs 2 and 3. After each round of insertion and FLP-mediated excision of the SAT1 flipper cassette the resulting strains were analysed by Southern hybridization with upstream and downstream probes of the target genes to confirm their specific inactivation and to exclude, as far as possible, undesired recombination events involving the previously inactivated loci. The absence of the target genes from the genome of the mutants was also confirmed by hybridization with the corresponding ORFs (data not shown). Apart from the deletion of the SAP genes, the final mutants should therefore be identical with the wild-type parental strain SC5314.

\section{SAP2, but not SAP4-SAP6, is required for utilization of protein as a nitrogen source}

A well-known and easily testable function of the Saps is the degradation of proteins for use as a nitrogen source (Staib, 1965). In YCB-BSA medium, which contains BSA as the sole nitrogen source, expression of the SAP2 gene is specifically induced and allows growth of C. albicans. No significant expression of other $S A P$ genes occurs under these conditions and sap $2 \Delta$ mutants are unable to grow in this medium, but forced expression of most other SAP genes from an inducible promoter can fully or partially rescue the growth defect of sap $2 \Delta$ mutants (Hube et al., 1994, 1997; Staib et al., 2002b, 2008). Interestingly, the sap $4 \Delta$ sap5 $\Delta$ sap $6 \Delta$ triple mutants used in previous studies have been reported to have a similar growth defect as sap2 $\Delta$ mutants in this medium, and it was concluded that Sap4p, Sap5p or Sap6p is required for the induction of SAP2 expression (Sanglard et al., 1997). We therefore tested the capacity of our sap $4 \Delta$ sap5 5 sap6 $\Delta$ triple mutants to grow in YCB-BSA. As can be seen in Fig. 4, mutants lacking the SAP4-SAP6 genes grew as well as the wild-type parental strain SC5314, both at $30{ }^{\circ} \mathrm{C}$, which is used as the standard condition in our laboratory, and at $37{ }^{\circ} \mathrm{C}$, which was used in the experiments in which a growth defect of sap $4 \Delta \operatorname{sap} 5 \Delta$ sap6 $\Delta$ triple mutants was observed by other researchers (Sanglard et al., 1997). In contrast, the sap2d mutants failed to grow in YCB-BSA at both temperatures, in line with previous observations (Hube et al., 1997; Staib et al., 2002a, 2008). When the supernatants of the cultures were analysed by SDS-PAGE, we found that the BSA in the medium was degraded by the sap $4 \Delta$ sap5 $\Delta$ sap $6 \Delta$ triple mutants and comparable ampounts of Sap2p were produced by these mutants and the wild-type strain both at $30{ }^{\circ} \mathrm{C}$ and at $37{ }^{\circ} \mathrm{C}$ (Fig. 5). These results demonstrate that SAP2, but not any of the SAP4-SAP6 genes, is required for growth of $C$. albicans on BSA as the sole nitrogen source and Sap $2 \mathrm{p}$ is normally expressed in the absence of SAP4-SAP6. Apparently, there are differences in the phenotypes of sap4 $4 a p 5 \Delta$ sap6 $\Delta$ mutants constructed previously from strain CAI4 and those generated in the present study from the wild-type strain SC5314.

\section{SAP1-SAP6 are not required for invasion and damage of reconstituted human epithelia}

We then tested the capacity of our mutants to invade and damage epithelial tissue during in vitro infection. In an initial set of experiments, all single mutants lacking one of the SAP1-SAP6 genes were used for infection of RHE; however, we did not observe a virulence defect of any of these mutants (data not shown). As other SAP genes might be upregulated and compensate for the loss of individual Sap isoenzymes, we then used the triple mutants lacking all of SAP1-SAP3 or SAP4-SAP6 in further infection experiments. In addition to the wild-type control strain SC5314, a nonfilamentous efg $1 \Delta$ mutant, which has been reported 

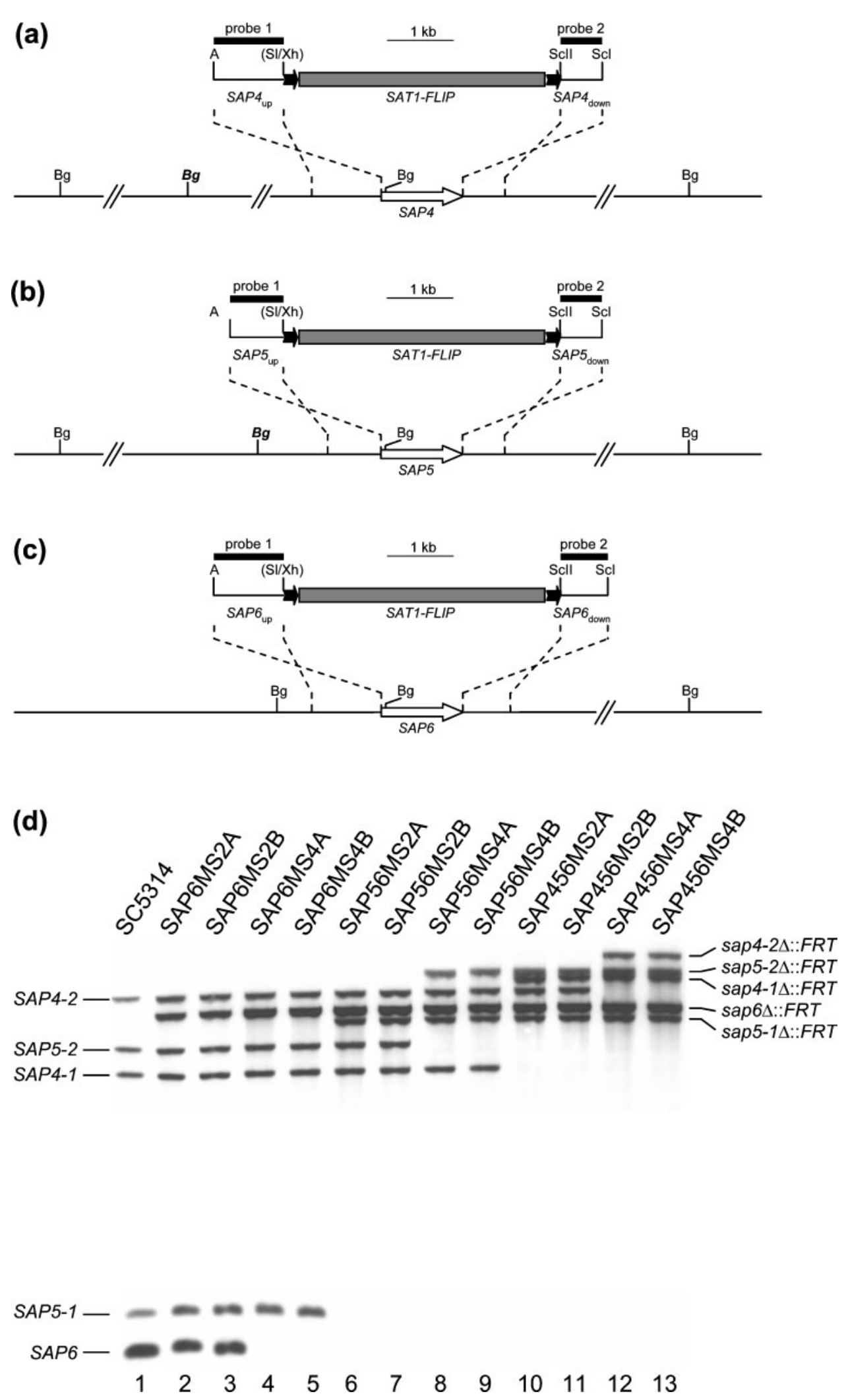

to be noninvasive in a similar epithelial infection model (Dieterich et al., 2002), was included for comparison. As shown in Fig. 6, no differences between the wild-type and either of the triple mutants in their capacity to invade and damage vaginal RHE could be observed. In each case, yeast and hyphal cells could be seen penetrating throughout the epithelium to the supporting filter. In contrast, the efg $1 \Delta$ mutant was unable to invade and damage the epithelium 
Fig. 3. Construction of sap $4 \Delta$ sap $5 \Delta$ sap6 $\Delta$ triple mutants. (a-c) Structure of the deletion cassettes from plasmids pSAP4MS2 (a), pSAP5MS2 (b) and pSAP6MS2 (c), which were used to delete the SAP4, SAP5 and SAP6 alleles, respectively, and genomic structure of the wild-type loci in strain SC5314. The SAP4-SAP6 coding regions are represented by white arrows and the upstream and downstream regions by the solid lines. Other details are as described in the legend to Fig. 2. The polymorphic Bgll sites are in bold italic. (d) Southern hybridization of Bg/ll-digested genomic DNA of the parental strain SC5314 and the indicated mutants with the SAP6-derived probe 1, which also cross-hybridizes with SAP4 and SAP5. Lane 1, wild-type; lanes 2 and $3, S A P 6 / \operatorname{sap} 6 \Delta$; lanes 4 and 5 , sap6 $\Delta / \operatorname{sap} 6 \Delta$; lanes 6 and $7, S A P 5 / \operatorname{sap} 5 \Delta \operatorname{sap} 6 \Delta / \operatorname{sap} 6 \Delta$; lanes 8 and 9 ,

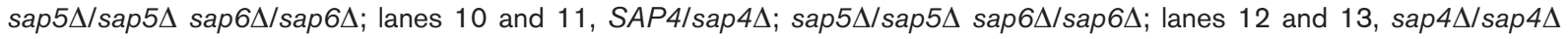
sap $5 \Delta / \operatorname{sap} 5 \Delta \operatorname{sap} 6 \Delta / \operatorname{sap} 6 \Delta$. Wild-type alleles are indicated on the left side of the blot and mutated alleles on the right.

and only yeast cells were found at the surface of the epithelium. These results suggested that none of the SAP1SAP6 genes is required for invasion of vaginal RHE, a conclusion that was further corroborated by the fact that, in our hands, the addition of the aspartic protease inhibitor
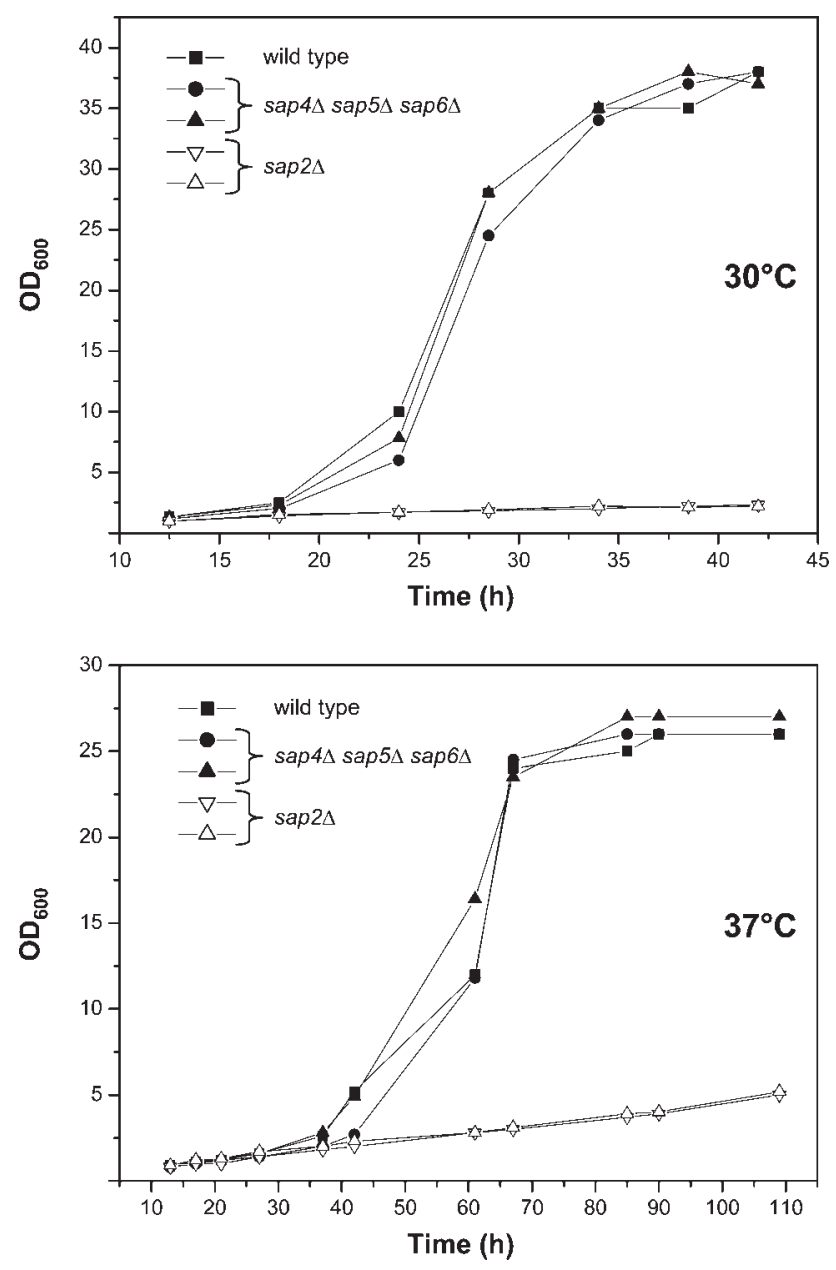

Fig. 4. Only $S A P 2$ is required for growth of C. albicans on proteins as the sole nitrogen source. YPD precultures of the wildtype strain $\mathrm{SC} 5314$, sap $2 \Delta$ single, and $\operatorname{sap} 4 \Delta \operatorname{sap} 5 \Delta$ sap $6 \Delta$ triple mutants were diluted $10^{-2}$ into YCB-BSA medium and incubated at $30{ }^{\circ} \mathrm{C}$ (top) or $37{ }^{\circ} \mathrm{C}$ (bottom). Growth was monitored by measuring the optical density of the cultures. Two independently constructed mutants were used in each case. pepstatin A did not affect the ability of the wild-type strain SC5314 to invade the vaginal RHE (Fig. 6). Similar results were obtained in experiments in which oral RHE was infected (data not shown).

Fungal invasion and tissue damage did not occur evenly within the whole RHE samples. To better compare and quantify the tissue damage caused by the various strains, we determined the LDH released from the epithelial cells after infection with C. albicans, as previously described (Schaller et al., 2003). Fig. 7 shows that there were no appreciable differences in the tissue damage caused by the wild-type and the sap mutants, and pepstatin A also did not reduce the tissue damage caused by the wild-type. Only the efg $1 \Delta$ mutant was unable to cause significant tissue
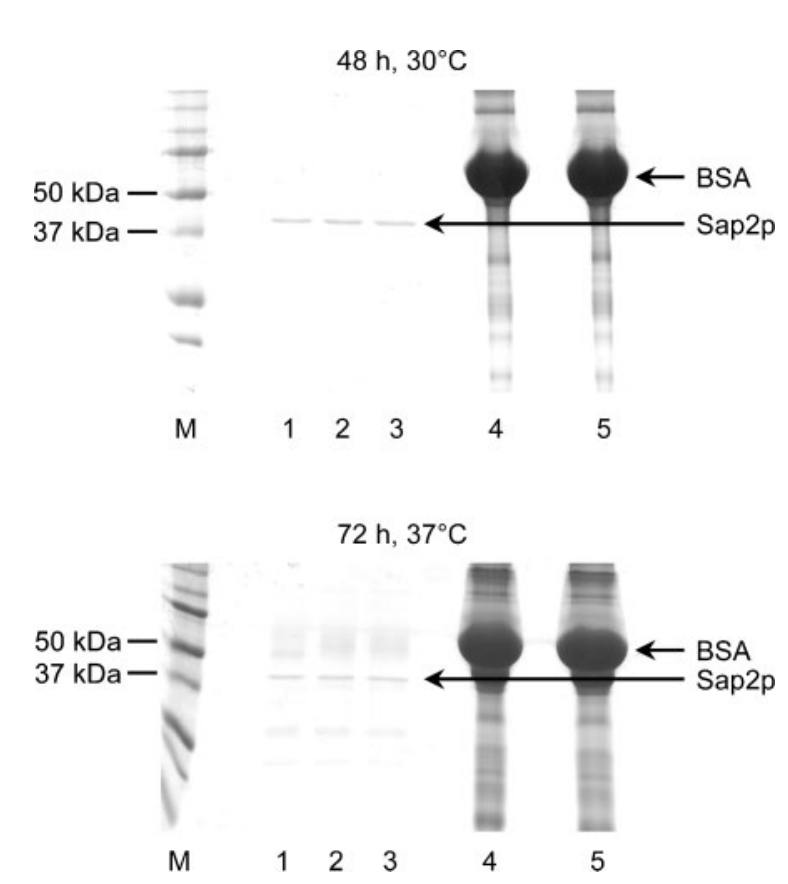

Fig. 5. Secretion of Sap2p by the wild-type strain SC5314 (lane 1) and the $\operatorname{sap} 4 \Delta \operatorname{sap} 5 \Delta$ sap $6 \Delta$ triple mutants SAP456MS $4 A$ (lane 2) and SAP456MS4B (lane 3) grown for $48 \mathrm{~h}$ at $30{ }^{\circ} \mathrm{C}$ (top) or $72 \mathrm{~h}$ at $37^{\circ} \mathrm{C}$ (bottom) in YCB-BSA. The culture supernatants of the strains were analysed by SDS-PAGE. Supernatants of the sap2 $\Delta$ mutants SAP2MS4A (lane 4) and SAP2MS4B (lane 5) were included for comparison. The bands corresponding to BSA and Sap $2 p$ are labelled by arrows. $M$, molecular size markers. 

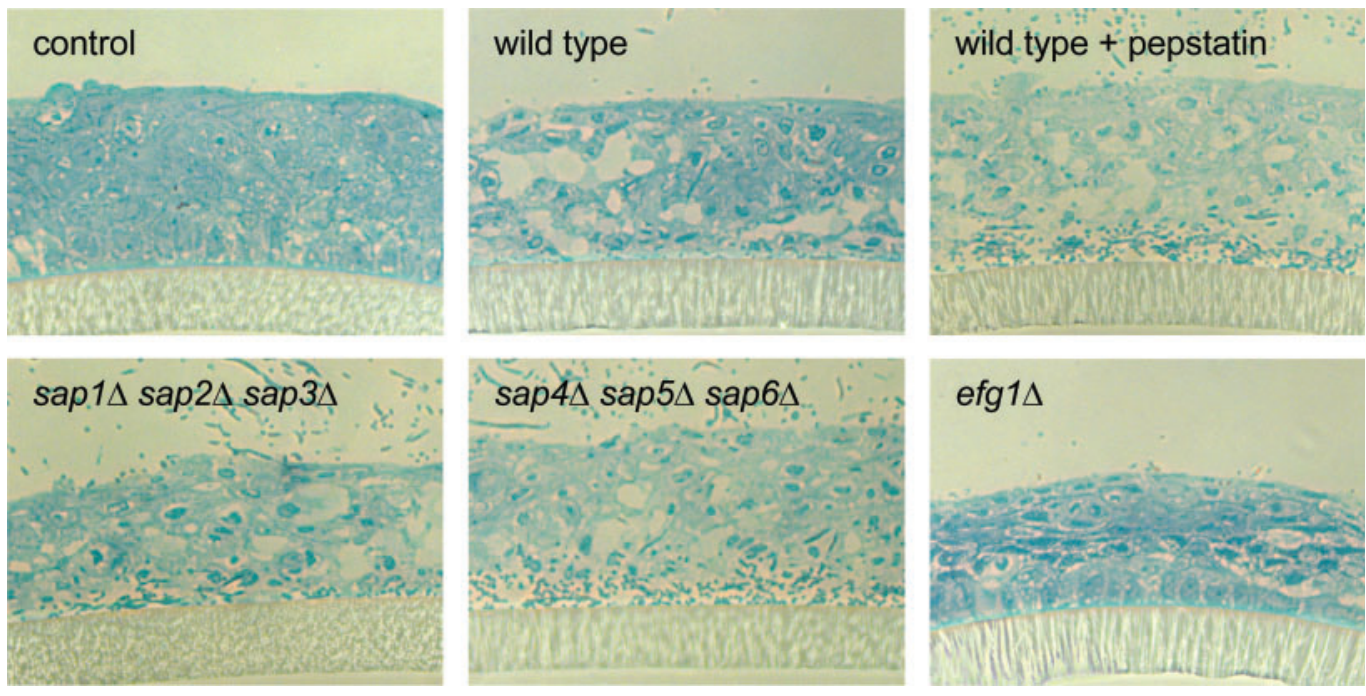

Fig. 6. Invasion of vaginal RHE by the C. albicans wild-type strain SC5314, the sap $1 \Delta \operatorname{sap} 2 \Delta$ sap3 $\Delta$ triple mutants SAP123MS4C and SAP123MS4D, the sap4 $\Delta$ sap5 $\Delta$ sap6 $\Delta$ triple mutants SAP456MS4A and SAP456MS4B, and the efg $1 \Delta$ mutant Can33. The independently constructed series of sap mutants behaved identically and only one of them is shown in each case. Infection by the wild-type strain was also performed in the presence of the aspartic protease inhibitor pepstatin A. An uninfected control sample is shown for comparison. After $48 \mathrm{~h}$ of infection, the tissue was processed for microscopy as described in Methods.

damage. Similar results were obtained in both vaginal (Fig. 7a) and oral (Fig. 7b) RHE infection models. We conclude from these experiments that Saps are not required for invasion of RHE by C. albicans.

\section{DISCUSSION}

The role of the Saps of C. albicans in the pathogenicity of the fungus has been investigated in numerous studies (for a comprehensive review, see Naglik et al., 2003a). Various laboratories have analysed the gene expression pattern of the SAP gene family during infection, as it might provide clues about the role of individual Sap isoenzymes in the host-pathogen interaction. The recombination-based IVET is highly useful for the detection of even a transient in vivo induction of genes that, like SAP1-SAP6, are not significantly expressed under standard growth conditions in vitro. An additional advantage of this reporter system is that the activation of a target gene promoter can be observed at the level of single cells. However, a limitation of the system is that only a yes or no answer is obtained for each cell recovered from infected tissue and, as previously noted, it may not be sensitive enough for genes that are expressed only at low levels (Staib et al., 1999, 2000, 2002b; Taylor et al., 2005). The sensitivity of the ecaFLP reporter gene was similar to that of the more frequently used GFP reporter gene when corresponding reporter strains were compared under identical conditions. Both reporter systems detected the induction of the SAP2 promoter in YCB-BSA medium in all cells of the population and also the activation of the SAP4 and SAP5 promoters during vaginal infection of mice, whereas no expression of the SAP1-SAP3 genes was observed in the latter model with either of the two reporter genes (Morschhäuser et al., 1998; Staib et al., 2000; Taylor et al., 2005). The expression of the phase-specific SAP1 gene was also easily detected in opaque cells of strain WO-1 using GFP as a reporter (Strauß et al., 2001). While our failure to detect expression of the SAP1 and $S A P 2$ genes during infection of vaginal RHE may therefore be due to a limited sensitivity of the FLP-based IVET, the expression levels of these genes in this infection model seem to be considerably below their fully induced state. Nevertheless, the importance of SAP1 and SAP2 for invasion and damage of vaginal RHE and of SAP1-SAP3 for infection of oral RHE has been demonstrated by the reduced virulence of mutants lacking the corresponding genes in these in vitro infection models (Schaller et al., $1998,1999,2003)$. In contrast, we were unable to confirm a role of any of the SAP1-SAP6 genes in the same infection models. Apart from a possible compensatory upregulation

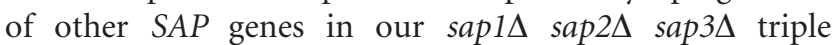
mutants, there are several possible explanations for the discrepancies in the results obtained in our present work and those of previous studies by other researchers. Although the RHE models have been reported to be highly reproducible (Naglik et al., 2003a), it seems that variabilities may nevertheless arise when they are used in different laboratories. Schaller et al. (1999) reported that the damage to oral RHE caused by infection with the wild-type strain SC5314 was reduced in the presence of the aspartic protease inhibitor pepstatin A, but we did not see such an effect in our present study. Pepstatin A completely 

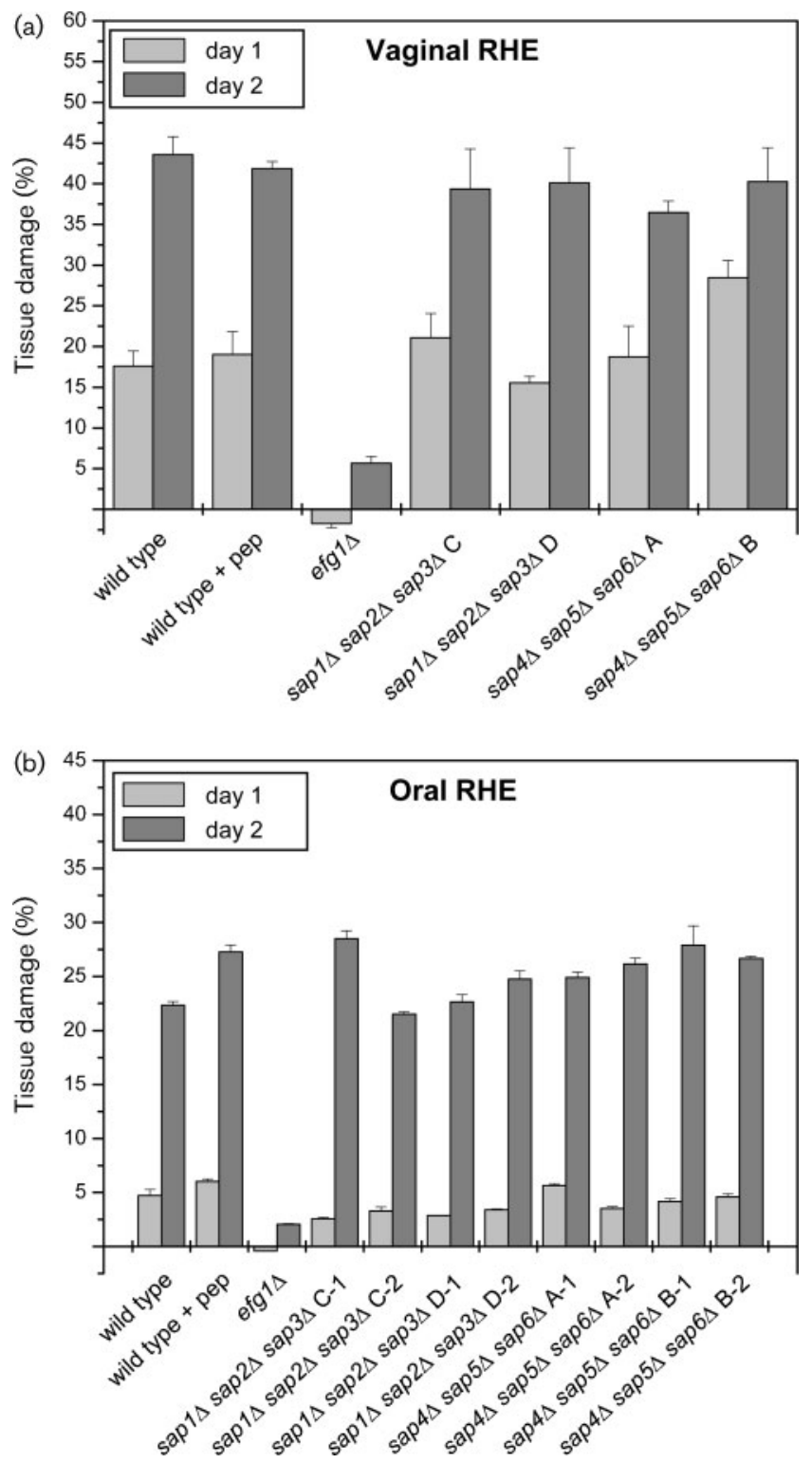

Fig. 7. Epithelial damage caused by the C. albicans wild-type strain SC5314 and sap $1 \Delta \operatorname{sap} 2 \Delta \operatorname{sap} 3 \Delta$ and sap $4 \Delta \operatorname{sap} 5 \Delta$ sap6 $\Delta$ triple mutants. Vaginal (a) or oral (b) RHE was infected with the indicated C. albicans strains. Infections with the wild-type strain SC5314 were also performed in the presence of pepstatin A (+pep). Tissue damage was determined by measuring the LDH activity in the supernatant after $24 \mathrm{~h}$ and $48 \mathrm{~h}$ as described in Methods. Values are the means $\pm S D$ from three replicate measurements. Two independently constructed sap1 $1 \Delta$ sap2 $\Delta$ sap3 $\Delta$ triple mutants (strains SAP123MS4C and SAP123MS4D) and sap4 4 sap5 $\Delta$ sap6 $\Delta$ triple mutants (strains SAP456MS4A and SAP456MS4B) were used in these experiments. Infection of the oral RHE (b) was performed in duplicate for all sap mutants, as indicated by the suffix. inhibits Sap-dependent growth in YCB-BSA medium at even lower concentrations than those used in the infection assays (Staib et al., 2008); therefore, a contribution of the Saps to tissue damage should have been detected, although we can not exclude the possibility that pepstatin A did not fully inhibit Sap activity under the conditions used in the RHE infection experiments. These results indicate that the differences observed in this and previous studies with respect to the role of the Saps for invasion of RHE can not solely be attributed to phenotypic differences of the constructed deletion mutants. Differences in the experimental setup may therefore cause invasion of RHE to be protease-dependent or not. In contrast to the sap mutants, an efg $1 \Delta$ mutant that had previously been reported to be noninvasive in a similar epithelial invasion model (Dieterich et al., 2002) was also unable to invade and damage vaginal and oral RHE in our hands. An alternative possible explanation for the differences in the effect of pepstatin A on the ability of the wild-type strain SC5314 to damage RHE is that the stocks of this strain maintained in various laboratories are not identical and may vary in their dependence on Sap activity for epithelial invasion.

Apart from these considerations, there also seem to be differences between the sap mutants constructed previously from the auxotrophic laboratory strain CAI4 and those generated in the present study from its prototrophic parental strain SC5314. In agreement with the gene expression pattern, we found that only $S A P 2$, but none of the other SAP genes tested, was required for growth of $C$. albicans in YCB-BSA medium, i.e. when proteins are the only available nitrogen source. In contrast, Sanglard et al. (1997) found that a mutant lacking the SAP4-SAP6 genes also failed to grow in this medium and they concluded that one of the corresponding proteases is required for SAP2 expression. They did not report whether mutants lacking only one or two of the SAP4-SAP6 genes exhibited the same growth defect and if reintroduction of any of the genes into the triple mutant rescued the growth defect. The sap $4 \Delta$ sap5 5 sap $6 \Delta$ triple mutants constructed in our present study secreted wild-type levels of Sap2p (see Fig. 5), demonstrating that SAP2 expression does not depend on any of those other proteases.

The importance of Saps for tissue invasion and damage seems to depend on the infection model used. For example, when the interaction of mutants lacking one of the SAP1SAP3 genes with endothelial cells was investigated, only Sap2p, but not Sap1p or Sap3p, was found to contribute to the ability of $C$. albicans to damage endothelial cells (Ibrahim et al., 1998). Other researchers found that proteases mediate invasion of $C$. albicans into human oral mucosa by degrading E-cadherin, as E-cadherin degradation was completely inhibited in the presence of protease inhibitors (Villar et al., 2007). In this case, Sap5p was implicated in tissue invasion, as forced overexpression of SAP5 rescued the invasion defect of a rim101 mutant, in which expression of the SAP4-SAP6 genes was severely reduced. On the other hand, C. albicans can also invade 
epithelial and endothelial cells by inducing its own endocytosis (Phan et al., 2007). These studies and our present work indicate that the importance of the Saps in general, and of individual Sap isoenzymes, for the virulence of $C$. albicans varies strongly, depending on the infection model, with even minor differences in the experimental setup having a significant impact on the dependence on protease activity for successful invasion and establishment in various host niches. New and more sophisticated animal models of superficial and disseminated Candida infections have been established in the past years and continue to be developed (de Repentigny, 2004). The set of mutants generated in this study from the wild-type model strain SC5314, which lack single or multiple SAP genes, will be a valuable tool to study the role of these enzymes in the hostpathogen interaction in more detail.

\section{ADDENDUM}

In a related paper in this issue of Microbiology, Naglik et al. (2008), using quantitative real-time RT-PCR, now also report that only SAP5, but not the other SAP genes, is significantly upregulated during infection of RHE and that the SAP1-SAP6 genes are not required for invasion of RHE, which is in contrast to their previous results and completely supports our findings. However, they observe a partial inhibition of RHE invasion and damage by $C$. albicans in the presence of the aspartic protease inhibitor pepstatin A.

\section{ACKNOWLEDGEMENTS}

We thank Steffen Rupp for providing the efg1s mutant Can33 and Peter Staib for critical reading of the manuscript. Sequence data for C. albicans were obtained from the Candida Genome Database (http://www.candidagenome.org/). This study was supported by the Deutsche Forschungsgemeinschaft (DFG grant MO 846/1 and SFB630).

\section{REFERENCES}

Bain, J. M., Stubberfield, C. \& Gow, N. A. (2001). Ura-statusdependent adhesion of Candida albicans mutants. FEMS Microbiol Lett 204, 323-328.

Brand, A., MacCallum, D. M., Brown, A. J., Gow, N. A. \& Odds, F. C. (2004). Ectopic expression of URA3 can influence the virulence phenotypes and proteome of Candida albicans but can be overcome by targeted reintegration of URA3 at the RPS10 locus. Eukaryot Cell 3, 900-909.

Cheng, S., Nguyen, M. H., Zhang, Z., Jia, H., Handfield, M. \& Clancy, C. J. (2003). Evaluation of the roles of four Candida albicans genes in virulence by using gene disruption strains that express URA3 from the native locus. Infect Immun 71, 6101-6103.

De Bernardis, F., Cassone, A., Sturtevant, J. \& Calderone, R. (1995). Expression of Candida albicans SAP1 and SAP2 in experimental vaginitis. Infect Immun 63, 1887-1892.

De Bernardis, F., Arancia, S., Morelli, L., Hube, B., Sanglard, D., Schafer, W. \& Cassone, A. (1999). Evidence that members of the secretory aspartyl proteinase gene family, in particular SAP2, are virulence factors for Candida vaginitis. J Infect Dis 179, 201-208.

de Repentigny, L. (2004). Animal models in the analysis of Candida host-pathogen interactions. Curr Opin Microbiol 7, 324-329.

Dieterich, C., Schandar, M., Noll, M., Johannes, F. J., Brunner, H., Graeve, T. \& Rupp, S. (2002). In vitro reconstructed human epithelia reveal contributions of Candida albicans EFG1 and CPH1 to adhesion and invasion. Microbiology 148, 497-506.

Felk, A., Kretschmar, M., Albrecht, A., Schaller, M., Beinhauer, S., Nichterlein, T., Sanglard, D., Korting, H. C., Schafer, W. \& Hube, B. (2002). Candida albicans hyphal formation and the expression of the Efg1-regulated proteinases Sap4 to Sap6 are required for the invasion of parenchymal organs. Infect Immun 70, 3689-3700.

Fonzi, W. A. \& Irwin, M. Y. (1993). Isogenic strain construction and gene mapping in Candida albicans. Genetics 134, 717-728.

Gillum, A. M., Tsay, E. Y. \& Kirsch, D. R. (1984). Isolation of the Candida albicans gene for orotidine-5' -phosphate decarboxylase by complementation of S. cerevisiae ura3 and E. coli pyrF mutations. Mol Gen Genet 198, 179-182.

Hube, B., Monod, M., Schofield, D. A., Brown, A. J. \& Gow, N. A. (1994). Expression of seven members of the gene family encoding secretory aspartyl proteinases in Candida albicans. Mol Microbiol 14, 87-99.

Hube, B., Sanglard, D., Odds, F. C., Hess, D., Monod, M., Schafer, W., Brown, A. J. \& Gow, N. A. (1997). Disruption of each of the secreted aspartyl proteinase genes SAP1, SAP2, and SAP3 of Candida albicans attenuates virulence. Infect Immun 65, 3529-3538.

Ibrahim, A. S., Filler, S. G., Sanglard, D., Edwards, J. E., Jr \& Hube, B. (1998). Secreted aspartyl proteinases and interactions of Candida albicans with human endothelial cells. Infect Immun 66, 3003-3005.

Köhler, G. A., White, T. C. \& Agabian, N. (1997). Overexpression of a cloned IMP dehydrogenase gene of Candida albicans confers resistance to the specific inhibitor mycophenolic acid. $J$ Bacteriol 179, 2331-2338.

Kretschmar, M., Hube, B., Bertsch, T., Sanglard, D., Merker, R., Schroder, M., Hof, H. \& Nichterlein, T. (1999). Germ tubes and proteinase activity contribute to virulence of Candida albicans in murine peritonitis. Infect Immun 67, 6637-6642.

Kwon-Chung, K. J., Lehman, D., Good, C. \& Magee, P. T. (1985). Genetic evidence for role of extracellular proteinase in virulence of Candida albicans. Infect Immun 49, 571-575.

Lay, J., Henry, L. K., Clifford, J., Koltin, Y., Bulawa, C. E. \& Becker, J. M. (1998). Altered expression of selectable marker URA3 in genedisrupted Candida albicans strains complicates interpretation of virulence studies. Infect Immun 66, 5301-5306.

Macdonald, F. \& Odds, F. C. (1983). Virulence for mice of a proteinase-secreting strain of Candida albicans and a proteinasedeficient mutant. J Gen Microbiol 129, 431-438.

Millon, L., Manteaux, A., Reboux, G., Drobacheff, C., Monod, M., Barale, T. \& Michel-Briand, Y. (1994). Fluconazole-resistant recurrent oral candidiasis in human immunodeficiency virus-positive patients: persistence of Candida albicans strains with the same genotype. J Clin Microbiol 32, 1115-1118.

Morschhäuser, J., Michel, S. \& Hacker, J. (1998). Expression of a chromosomally integrated, single-copy GFP gene in Candida albicans, and its use as a reporter of gene regulation. Mol Gen Genet 257, 412420.

Naglik, J. R., Challacombe, S. J. \& Hube, B. (2003a). Candida albicans secreted aspartyl proteinases in virulence and pathogenesis. Microbiol Mol Biol Rev 67, 400-428.

Naglik, J. R., Rodgers, C. A., Shirlaw, P. J., Dobbie, J. L., FernandesNaglik, L. L., Greenspan, D., Agabian, N. \& Challacombe, S. J. 
(2003b). Differential expression of Candida albicans secreted aspartyl proteinase and phospholipase B genes in humans correlates with active oral and vaginal infections. J Infect Dis 188, 469-479.

Naglik, J. R., Moyes, D., Makwana, J., Kanzaria, P., Tsichlaki, E., Weindl, G., Tappuni, A. R., Rodgers, C. A., Woodman, A. J. \& other authors (2008). Quantitative expression of the Candida albicans secreted aspartyl proteinase gene family in human oral and vaginal candidiasis. Microbiology 154, 3266-3280.

Odds, F. C. (1988). Candida and Candidosis: a Review and Bibliography. London, UK: Baillière Tindall.

Phan, Q. T., Myers, C. L., Fu, Y., Sheppard, D. C., Yeaman, M. R., Welch, W. H., Ibrahim, A. S., Edwards, J. E., Jr \& Filler, S. G. (2007). Als3 is a Candida albicans invasin that binds to cadherins and induces endocytosis by host cells. PLoS Biol 5, e64.

Reuß, O., Vik, A., Kolter, R. \& Morschhäuser, J. (2004). The SAT1 flipper, an optimized tool for gene disruption in Candida albicans. Gene 341, 119-127.

Sanglard, D., Hube, B., Monod, M., Odds, F. C. \& Gow, N. A. (1997). A triple deletion of the secreted aspartyl proteinase genes SAP4, SAP5, and SAP6 of Candida albicans causes attenuated virulence. Infect Immun 65, 3539-3546.

Schaller, M., Schafer, W., Korting, H. C. \& Hube, B. (1998). Differential expression of secreted aspartyl proteinases in a model of human oral candidosis and in patient samples from the oral cavity. Mol Microbiol 29, 605-615.

Schaller, M., Korting, H. C., Schafer, W., Bastert, J., Chen, W. \& Hube, B. (1999). Secreted aspartic proteinase (Sap) activity contributes to tissue damage in a model of human oral candidosis. Mol Microbiol 34, 169-180.

Schaller, M., Bein, M., Korting, H. C., Baur, S., Hamm, G., Monod, M., Beinhauer, S. \& Hube, B. (2003). The secreted aspartyl proteinases Sap1 and Sap2 cause tissue damage in an in vitro model of vaginal candidiasis based on reconstituted human vaginal epithelium. Infect Immun 71, 3227-3234.

Schofield, D. A., Westwater, C., Warner, T., Nicholas, P. J., Paulling, E. E. \& Balish, E. (2003). Hydrolytic gene expression during oroesophageal and gastric candidiasis in immunocompetent and immunodeficient gnotobiotic mice. J Infect Dis 188, 591-599.

Sharkey, L. L., Liao, W. L., Ghosh, A. K. \& Fonzi, W. A. (2005). Flanking direct repeats of his $G$ alter URA3 marker expression at the HWP1 locus of Candida albicans. Microbiology 151, 1061-1071.
Staib, F. (1965). Serum-proteins as nitrogen source for yeastlike fungi. Sabouraudia 4, 187-193.

Staib, F. (1969). Proteolysis and pathogenicity of Candida albicans strains. Mycopathol Mycol Appl 37, 345-348.

Staib, P., Kretschmar, M., Nichterlein, T., Köhler, G., Michel, S., Hof, H., Hacker, J. \& Morschhäuser, J. (1999). Host-induced, stagespecific virulence gene activation in Candida albicans during infection. Mol Microbiol 32, 533-546.

Staib, P., Kretschmar, M., Nichterlein, T., Hof, H. \& Morschhäuser, J. (2000). Differential activation of a Candida albicans virulence gene family during infection. Proc Natl Acad Sci U S A 97, 6102-6107.

Staib, P., Kretschmar, M., Nichterlein, T., Hof, H. \& Morschhäuser, J. (2002a). Host versus in vitro signals and intrastrain allelic differences in the expression of a Candida albicans virulence gene. Mol Microbiol 44, 1351-1366.

Staib, P., Kretschmar, M., Nichterlein, T., Hof, H. \& Morschhäuser, J. (2002b). Transcriptional regulators Cphlp and Efglp mediate activation of the Candida albicans virulence gene SAP5 during infection. Infect Immun 70, 921-927.

Staib, P., Lermann, U., Blass-Warmuth, J., Degel, B., Würzner, R., Monod, M., Schirmeister, T. \& Morschhäuser, J. (2008). Tetracyclineinducible expression of individual secreted aspartic proteases in Candida albicans allows isoenzyme-specific inhibitor screening. Antimicrob Agents Chemother 52, 146-156.

Strauß, A., Michel, S. \& Morschhäuser, J. (2001). Analysis of phasespecific gene expression at the single-cell level in the white-opaque switching system of Candida albicans. J Bacteriol 183, 3761-3769.

Taylor, B. N., Staib, P., Binder, A., Biesemeier, A., Sehnal, M., Röllinghoff, M., Morschhäuser, J. \& Schröppel, K. (2005). Profile of Candida albicans-secreted aspartic proteinase elicited during vaginal infection. Infect Immun 73, 1828-1835.

Villar, C. C., Kashleva, H., Nobile, C. J., Mitchell, A. P. \& DongariBagtzoglou, A. (2007). Mucosal tissue invasion by Candida albicans is associated with E-cadherin degradation, mediated by transcription factor Rim101p and protease Sap5p. Infect Immun 75, 2126-2135.

White, T. C. \& Agabian, N. (1995). Candida albicans secreted aspartyl proteinases: isoenzyme pattern is determined by cell type, and levels are determined by environmental factors. J Bacteriol 177, 5215-5221.

Edited by: J. G. Berman 